\title{
Here be dragons: Exploring Cartography in Educational Theory and Research
}

\author{
CLAUDIA W. RUITENBERG \\ University of British Columbia (Canada)
}

\begin{abstract}
In the literature on complexity theory it has been noted that the increasing interdependence, non-linearity, and adaptiveness of social and other systems require forms of representation that can accommodate such complexity. In this essay I argue for examining the possibilities of cartography (mapmaking) in and of educational theory and research. Cartography offers alternative forms of representation that are better suited to capturing complexity. The performativity of cartographic representations, moreover, produces different knowledge. I present four features of educational theory, research, and practice that suggest the relevance of cartography. The first is the widespread use of narrative models of representation and interpretation. Narrative discourse typically emphasizes temporality; maps are an alternative or complementary discourse that visualize and help to examine the spatial character of educational experience. The second feature is that spatial metaphors abound in educational discourse, including the recently ubiquitous metaphor of the web or network. Cartographic discourse is well suited for representing, interpreting, and critiquing these metaphors. The third feature is the increased use of hyperlinked information in educational theory and practice. Maps are better suited to capture and to enable the questioning of the rhizomatic interconnections of hypertextual reading and writing practices than more linearly organized discourse. The fourth feature of education is that it is a social institution that plays a central role in the social positioning of subjects. When the discursive and physical mechanisms through which students and teachers are separated, categorized, ranked, and assessed are cartographically represented and analyzed, new questions can emerge about these mechanisms of power.
\end{abstract}




\section{Introduction}

In their opening piece of the first issue of Complicity, editors Brent Davis, Renata Phelps and Kristopher Wells (2004) note,

A prominent theme across the current complexity science literatures is that the linear narrative and the Euclidean image are inadequate to depict the emergence and the behavior of a complex form. Rather, instances of complex emergence call for webbed, multithreaded tales and nested, scale independent geometries to accommodate forms that can become more intricate, more dense, more pregnant with possibilities. (p. 4)

Davis, Phelps and Wells signal that the increasing interdependence, non-linearity, and adaptiveness of social and other systems require forms of representation that can accommodate such complexity. In this essay I address this issue of depiction and representation, and examine the possibilities that cartography (mapmaking) offers educational theorists and researchers. Currently, many theorists and researchers use language that refers to cartography: they speak or write of "mapping" a field or range of phenomena, but few actually create visual maps. As Gustavo Fischman (2001) observes, "the reliance on words and numbers among educational researchers and the general tendency of dismissing images is generalized and crosses academic traditions, theoretical orientations, and research methods" (p. 28). I will argue that there are good reasons for changing this tendency, and for examining the possibilities of cartography (mapmaking) in and of educational theory and research.

On old maps, the phrase "Here be dragons" (or, more likely, the Latin Hic sunt dracones) indicated that which lay beyond the world as it was known at the time. In this paper I explore the possibilities of cartography as a largely uncharted territory in educational theory. Although some work on social cartography has been done in the area of comparative education (Paulston \& Liebman, 1994; Paulston, 1996; 1999; Liebman, 1996), cartographic representations are not common in educational theory, nor have the functions and effects of cartographic representation been fully considered and studied in educational circles.

Maps are visual representations of locations, positions, distances, relations, and so forth, and although perhaps the most obvious examples of maps are geographical (world maps, road maps, etc.), maps are also used to represent other, less tangible, objects and phenomena (e.g., concept maps, process flow charts.) In this paper I will use the term "cartography" to refer to the theory and practice of all forms of mapping, both geographic and non-geographic. In doing so, I follow Paulston $(1996 ; 1999)$ in his use of the term, rather than accepting the narrower use proposed by Joseph Seppi (1996). Seppi allows for an open use of the term "map" but suggests that "cartography" be reserved for the discipline of abstracting measurable 
features as forms or shapes onto a two- or three-dimensional plane (p. 122). He uses alternative terms such as "cognography" and "phenomenography" for the more free-form mapping of concepts, ideas, and phenomena, which Paulston calls "social cartography."

Social cartography in the most general sense of the word can be defined as "the art and science of mapping ways of seeing" (Paulston, 1996, p. xv). Often, social cartography is concerned with the locations, relations, and movement of ideas, persons, or social groups in social space. Tactical cartography can be considered a subset of social cartography, and encompasses projects that make use of cartographic tools and methods in order to show power relations between groups and individuals, and hence make those power relations available for critique. Critical cartography is concerned with "redefining what constitutes a map and what constitutes 'mapping practice'" and offers critiques of traditional cartography insofar as it remains oblivious to absence and exclusion, change, interpretive perspective, and so on (D'Ignazio, 2005).

In this paper I will present several reasons to examine the possibilities of, in particular, social, critical, and tactical cartography in educational theory. It might be observed that cartography offers new possibilities for the humanities and social sciences in general, and that education is a subset or field of application of the humanities or social sciences. There certainly are changes in social contexts which affect the humanities and social sciences, including educational theory and research, and which have led to an increased attention to spatiality. A notable example is transnational migration and the attendant increase in cultural diversity and interest in hybrid, nomadic, and diasporic identities (e.g., Braidotti, 2005). There also are changes in academic and epistemic structures that affect the humanities and social sciences, including educational theory and research. Increased inter-, trans-, cross-, and postdisciplinarity is one example pointing to the relevance of cartographic analysis of boundaries and liminal zones, proximity and distance. Another example is the critique of the mind-body dualism, and the renewed attention to the body and its movement in space. In this paper, however, I will not discuss these more general changes to social contexts, but rather limit myself to four features that are distinctive to education, and which suggest cartography is worth examining specifically in the context of educational theory and research.

An important assumption guiding my inquiries will be that maps are discursive: forms of representation, such as maps, never merely represent the world, but always also produce or constitute it. This assumption about maps follows the work of critical cartographer J. B. Harley (1988), who uses the term "cartographic 'discourse"' (p. 278) and notes that maps "are a class of rhetorical images[,] bound by rules which govern their codes and modes of social production, exchange and use just as surely as any other discursive form" (pp. 278-279). When I present cartographic discourse as an alterna- 
tive or complementary discourse I do so not because I believe it is somehow more neutral and less rhetorical than other discourse, but precisely because maps produce worlds different from those produced by other discourse, and this allows us to ask different kinds of questions. I concur with Harley's (1989/2001) suggestion that maps ought to be read deconstructively, but such a deconstructive reading requires that there are maps to be read at all.

The first feature of education that suggests cartography may be a relevant discourse is the widespread use of narrative models of representation and interpretation in both theory and practice. Narrative discourse typically emphasizes temporality and pays less attention to spatiality; maps are an alternative or complementary discourse that can highlight and help to examine the spatial character of educational experience. The second feature of education is that spatial metaphors abound in educational discourse, including the recently ubiquitous metaphor of the web or network. Webs of discourse, webs of power, information networks, and ecological networks are metaphors many people find helpful in thinking about educational theory and practice, and cartographic discourse is well suited for representing, interpreting, and critiquing such ideas. The third feature of education is the increased use of hyperlinked information in educational theory and practice. Maps are better suited to capture and to enable the questioning of the rhizomatic interconnections of hypertextual reading and writing practices than more linearly organized narrative discourse. The fourth feature of education is that it is a social institution that plays a central role in the social positioning of subjects. The analysis of Michel Foucault has been very instructive in pointing at the discursive and physical mechanisms deployed in education, which serve to separate, categorize, rank, and assess subjects. When such mechanisms are cartographically represented and analyzed, when they are made visible in a new way, new questions can emerge about the effects of and possible resistance to these mechanisms of power.

\section{How uncharted is this territory?}

In their 1994 article "An invitation to postmodern social cartography" Rolland Paulston and Martin Liebman invited scholars in comparative education to consider social cartography as a "secondary discourse style" that would enable a "visual dialogue" in the field (pp. 215-216). They follow urban cartographer Edward Soja's (1989) lead in reasserting the importance of space and spatial relations in the analysis of social phenomena. Also, they note that social cartography is especially relevant in an era where the single, unifying metanarrative has been replaced by a multitude of small narratives, each examining their own location in the social milieu. Paulston and Liebman suggest, 
The postmodern researcher in comparative education, who may also become a postmodern cartographer, prizes both the space within the social milieu and the possibilities for a more inclusive, if provisional, mapping of that space, motivating the creation of multiple, inclusive, and, therefore, antifoundational maps. (p. 222)

Paulston (1994) not only theorized but also practiced social cartography in comparative education and published "a macro-mapping of paradigms and theories in comparative and international education texts seen as an intellectual field" (as cited in Paulston \& Liebman, 1994, p. 224).

Figure 1. Paulston, 1994, reprinted in Paulston \& Liebman, 1994, p. 224

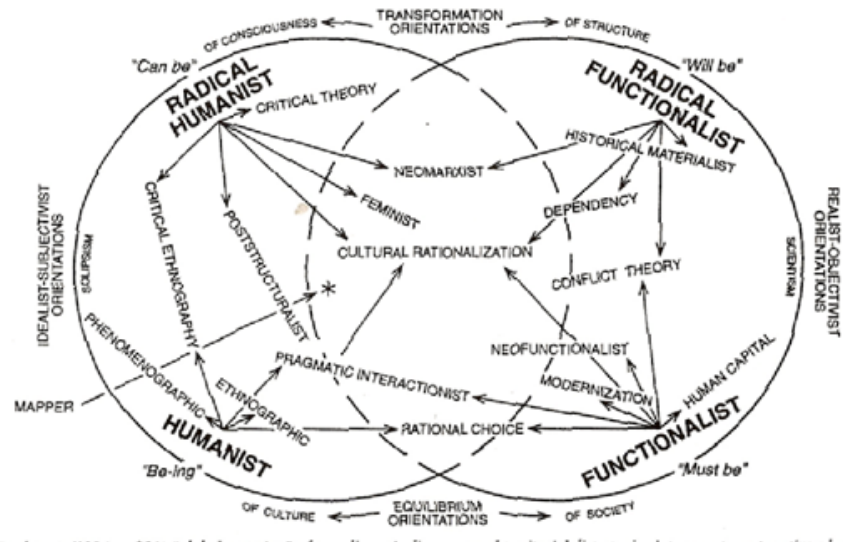

In 1999 Paulston published a new map of "knowledge positions constructing the postmodernity debate in comparative education" (p. 445). He characterized social cartography — which was now included as a knowledge position on the map —as "an oppositional postmodern strategy" which "seeks to open up meanings, to uncover limits within cultural fields, and to highlight reactionary attempts to seal borders and prohibit translations" (p. 454).

Figure 2. Paulston, 1999, p. 445

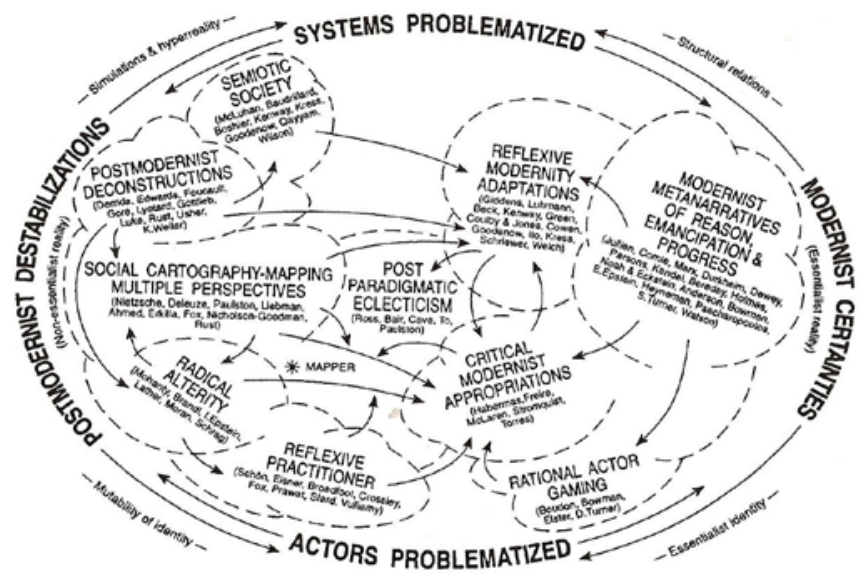


Beyond comparative education however, non-geographic uses of cartography tend to be, at best, tangentially related to education, and are not commonly part of discourses in educational theory. Artist Josh On (2004) uses tactical cartography in an interactive website to expose power connections in the United States between companies and institutions (including leading universities such as Harvard, Princeton, Duke, and Stanford) via their boards of directors. In a similar vein, Amy Metcalfe (in press) uses social network analysis to show the connections between North American corporations and higher education associations.

Figure 3. Metcalfe, 2006, forthcoming.

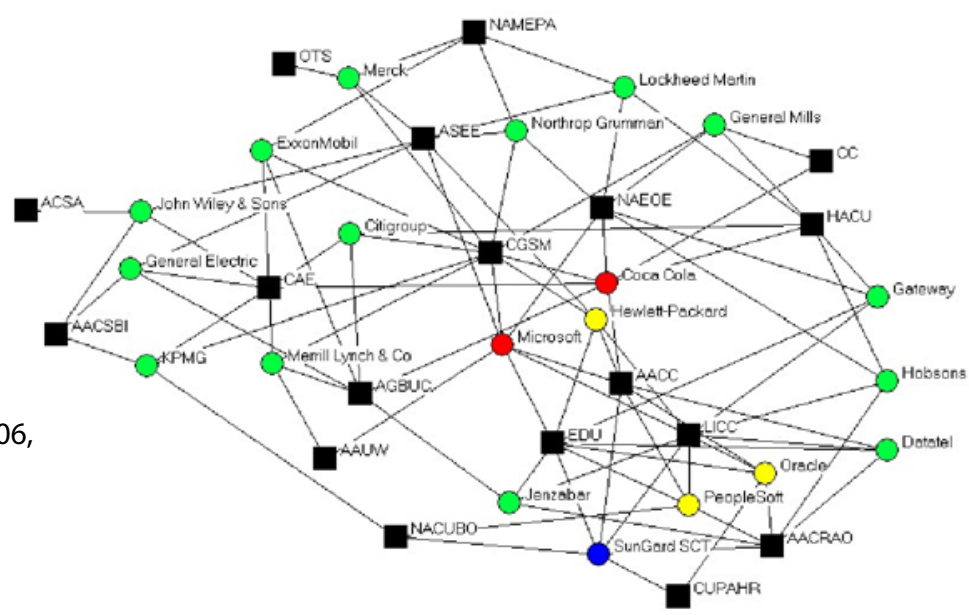

Metcalfe describes this tactical cartographic methodology as "somewhat new to education literature" and "rarely used in higher education scholarship." Govcom.org, an Amsterdam-based foundation directed by Richard Rogers, focuses on creating maps of "issue networks." Through the use of the Issue Crawler software, maps are generated that indicate what kind of organizations (.gov, .org, .com) are involved in debates on social issues. Who has used the Issue Crawler to create maps of and analyze the lives of educational issues? One result of the Issue Crawler was a map of the language used in various media to refer to the "security fence" ("separation barrier," "apartheid wall") being built in Israel. What would a map look like that positioned the language used by various scholars and agencies to refer to marginalized/disadvantaged / at-risk youth?

\section{Representation and performativity}

If visual representations were just that-visual representations-the use of mapping in and of education would be of little importance. Mapping would be just another way of representing the same theoretical or practical 
reality more commonly represented in narrative or argumentative text. But, as especially poststructuralist philosophers have argued, representations never merely represent; they also constitute and produce. Following this argument, cartographic discourse produces a different world than, say, narrative discourse. By discourse I mean "a historically, socially, and institutionally specific structure of statements, terms, categories, and beliefs" (Scott, 1988/1997, p. 759). In other words, a discourse consists not only of a particular body of signs (e.g., words), but also of the very categories and limits of intelligibility that make thinking, speaking and writing through that body of signs possible at all. Sarup (1998), drawing on the work of Foucault, explains discourse as a practice that systematically forms the objects of which it speaks (p. 64), thus emphasizing performativity as discursive feature.

Performativity is the power of discourse to bring about effects in the world. Contemporary work on performativity is based on the work of the English philosopher J. L. Austin (1911-1960) who first introduced the term "performative" to refer to a particular kind of speech: the kind that does not report or describe an action, but rather commits the action. In the case of a performative utterance, "in saying what I do, I actually perform that action" (Austin, 1962, p. 222). In saying "I invite you for dinner tomorrow" I actually issue the invitation; in saying "I apologize for my rudeness" I actually offer the apology. Later theorists such as Judith Butler and Jacques Derrida have shown that all language has performative force, and that the most common form of that force is not the single utterance, but rather the sedimentation of repeated discourse. Performativity is thus, in its most common form, not merely the power of discourse to produce effects, but, more specifically, the "power of discourse to produce effects through reiteration" (Butler, 1993, p. 20). In the case of educational theory and research, one of the effects brought about by repeated discourse is the relative positioning in the text and on the page of researcher and research subject.

Patti Lather and Chris Smithies (1997) are aware of the performative force of the representation of research. In Troubling the angels: Women living with $H I V / A I D S$, they deliberately disrupt the traditionally expected format of the research report or academic text. Lather and Smithies note that their book "is laid out so that, rather than only 'giving voice' to the stories of others, this is also a book about researchers both getting out of the way and getting in the way" (pp. xiii-xiv). Instead of a linear text in the researchers' voices, into which the voices of their research subjects are integrated, Lather and Smithies have split the page, letting the women in their research project speak in their own voices, separate from the researcher voices. Although they acknowledge that as researchers, they can never get entirely out of the way, they at least attempt not to "drown the poem of the other with the sound of [their] own voices, as the ones who know, the 'experts' about how people make sense of their lives and what searching for meaning means ..." (p. xvi). 
Lather and Smithies' intervention is spatial: they have literally positioned the words of the women in their research study on the page, and disrupted expectations of a smooth and linear text. In a reflection on this process, Lather (1996) notes that the layering and juxtaposition of text in Troubling the Angels made the text rhizomatic, "an open trajectory of loose resonating aggregates as a way to trace how the space of knowledge has changed its contours" ( $p$. 538). I will address the concept of the rhizome further in my discussion of the use of spatial metaphors in educational discourse. First, however, I turn to the prevalence of narrative structures in educational theory and practice.

\section{Time and space in narrative and cartographic representation}

The first reason for exploring the possibilities of cartography in educational theory is that the narrative paradigm is pervasive in both educational practice and theory. As Gordon \& Alexander (2005) sum up,

everyone 'does' narrative: discusses it; uses the term in theorizing; uses it as a research tool; extols its importance for child development, psychological health, and what have you; and recounts or analyzes his or her own and other people's life stories or personal narratives. (p. 134).

In educational research, specifically, the influence of the methodology of "narrative inquiry," developed by Jean Clandinin and Michael Connelly, is hard to miss. Connelly and Clandinin (1990) explain that, "the main claim for the use of narrative in educational research is that humans are storytelling organisms who, individually and socially, lead storied lives. The study of narrative, therefore, is the study of the ways humans experience the world" (p. 2). It is equally true, of course, that humans are embodied organisms who, individually and socially, occupy and move through space, and, following the logic proposed above, it could be claimed that the study of space, therefore, is the study of the way humans experience the world. Both of these perspectives are partial, as humans never move either through space or time but always through both, and time and space cannot be understood separately from each other. In current educational theory and research however, textual forms of representation that emphasize the temporal aspects of human experience dominate.

The cartographic emphasis on spatial relations complements and raises questions about narrative assumptions about time. Narrative is primarily the ordering of experience in time. Paul Ricoeur (1984), one of the key theorists of narrative, writes that "time becomes human time to the extent that it is organized after the manner of a narrative; narrative, in turn, is meaningful to the extent that it portrays the features of temporal experience" (p.3). Maps, by contrast, are forms of representation that emphasize spatiality. Spatial representation has different performative force: it constitutes the world it 
represents differently, makes different kinds of knowledge possible. Where narratives require the creation of plot, the drawing into a coherent whole of disconnected experiences and events, and the selection of a beginning and end, maps require the creation of spatial order, the selection of symbols, and the establishing of boundaries. When it is assumed that the study of narrative is the best or the most obvious way to study educational experience, it is easy to lose sight of the spatial qualities of educational experience, and of how other discursive forms might shed light on those.

I do not wish to replace narrative modes of representation but rather to put another mode beside them, so that the respective strengths and weaknesses of each mode can help us ask critical questions about the blind spots of the other. Mapping is not "better" than narrating in any general sense, but in certain contexts the strengths of cartographic discourse can help address the limitations of narrative discourse. In narrative representation relative position and distance, and the relation between centre and periphery need not be made specific. When ideas, phenomena, individuals, groups, and so on are mapped, the cartographer is forced to think very carefully about what is placed in the centre and what at the periphery, and where the boundaries are, but the nature of the relationship can be left unspecified more easily.

From the perspective of complexity theory it is important to emphasize the inseparability of space and time. Einstein's theory of relativity has shown time not to be absolute but relative, dependent on movement through space. Fritjof Capra (1982) acknowledges that, although physicists and mathematicians have had many years to become thoroughly familiar with relativity theory, "this has not helped our intuition very much [as] we have no direct sensory experience of the four-dimensional space-time..." (p. 89). Dynamic maps, showing the relative stability and the emergence of patterns in complex dynamic systems such as cognition and discourse are more helpful here than descriptions constrained by words and numbers. These maps are more than illustrations: they are an integral part of the ongoing research and questioning of these complex systems.

Michel de Certeau (1984) also emphasizes that temporal and spatial relations are not opposed or mutually exclusive: all temporal, narrative ordering takes place in a spatial context, and cartographic configurations change over time. Cartographic discourse, therefore, does not only include static two-dimensional maps, but also three-dimensional, layered, and dynamic maps. De Certeau discusses the itinerary as a "travel story," a story through space as well as time (p. 115). As many who have tried to find an unfamiliar destination will recognize, often a combination of written directions and a map are helpful, because a visual overview and a sequential description present different elements of human experience. This applies not only to the planning of physical trips, but also to the planning of curriculum. (After all, 
the Latin curriculum (from currere, to run) designated a (chariot) racetrack or course.) Cartographic discourse would push curriculum and course planners to examine the epistemological assumptions of the proposed learning movement. Typically, a course syllabus is written quite narratively: "in the first week, we will look at A and B, in the second week, we will discuss $C$ and D," and so on. A visual map of the journey through the course or the larger curriculum would demand more attention to the angle from which the curriculum or course has been put together: who is at the centre, and who is at the periphery? How close or distant are the various theories or phenomena that are discussed? What ground is not covered at all?

\section{Spatial metaphors and the network as root metaphor}

The second reason for exploring the possibilities of cartography in educational theory is the proliferation of spatial metaphors in educational discourse, and the rise of new metaphors, such as the web and network. Spatial metaphors are not new in educational discourse. Plato's "Allegory of the Cave" is perhaps the most famous spatial metaphor for education: the process of education is presented as a "leading up" out of the darkness of the cave (out of the Realm of Appearances) into the light of the sun (into the Realm of the Forms). In other metaphors the "upward path" of education does not lead out of a cave, but rather up a mountain. Ormell (1996) presents "eight metaphors for 'real' or 'genuine' education" (p. 68), three of which are related to the spatial metaphor of education as a journey up a mountain. Ormell conceives of the curriculum as "a definite, recognized named mountain, which requires effort and stamina to climb" and which should be "a mountain sufficiently prominent that it can be seen from a distance ..." (p. 72). Furthermore, the student should be able to gauge her or his progress in the trek up the mountain by the curricular equivalent of the altimeter: formative assessment (p. 73). Finally, when the climber reaches the summit, the effort is rewarded with "a 'local synthesis': a single viewpoint or vantage-point from which a great tract of country (knowledge) can be seen" (p. 73).

In contemporary postmodern discourse, including discourse in education, spatial metaphors seem to be especially popular, but, in contrast to the solidity of the cave or mountain, the new spatial metaphors emphasize the shifting and tenuous nature of spaces. Cracks and fissures are observed, passages and pathways sought (e.g., Martusewicz, 2001), interstitial spaces explored. Michael Peters (1996) notes that, "the spatialisation of knowledge and education in the postmodern age is based on the 'soft architecture' of the network which increasingly defines the nature of our institutions and our subjectivities" (p. 100, as cited in Usher, 2002, p. 43). 
One might even propose that the network (or web) has become a new root metaphor. A root metaphor, explains Stephen Pepper (1961), is the analogy or metaphor at the heart of a "world hypothesis," a theory about what the world is and how it functions. Pepper claims that there are four viable and mutually exclusive world hypotheses, and refers to them as formism, mechanism, contextualism, and organicism (pp. 98-99). Although in Pepper's model the network might be considered a metaphor belonging in the contextualist or organicist world hypothesis, the specific image of the web or network is so predominant in contemporary postindustrial culture and society that I believe it warrants a separate discussion as root metaphor. Steve Pile and Nigel Thrift's (1995) suggestion that "root" metaphors are replaced by "route" metaphors is particularly salient in this discussion (p. 10, as cited in Usher, 2002, p. 46).

Canadian political scientist Janice Gross Stein (2001) asserts that, "the network has become the most pervasive organizational image and the dominant form of social organization in post-industrial society" (p. 229). In this assessment she agrees with sociologist Manuel Castells (1996), who refers to networks as "the new social morphology" (p. 469). Examples of webs and networks are plentiful, the most obvious one perhaps being electronic networking via the internet and the World Wide Web, but expressions such as "webs of meaning" or "webs of discourse" are also becoming increasingly common.

Gilles Deleuze and Félix Guattari (1980/1987) have introduced the image of the rhizome, closely related to the network. A rhizome is an underground system of horizontally spreading rootstalks, such as of grass, potatoes, and ginger. Deleuze and Guattari distinguish the rhizome from the more vertical root and radicle as metaphors for types of books. Where both root-books and radicle-books are essentially unitary, rhizome-books (such as their own A Thousand Plateaus) are heterogeneous, multiplicitous and both internally and externally connected. Rhizomes always have "multiple entryways" (p. 12), and grow through "successive lateral offshoots in immediate connection with an outside" (p. 19). Deleuze and Guattari's introduction of the rhizome is a critique of the use of the metaphor of the tree, in which a spreading root system and crown are connected by a single, solid trunk. They write, "thought is not arborescent, and the brain is not a rooted or ramified matter. ... Many people have a tree growing in their heads, but the brain itself is much more a grass than a tree" (p. 15).

The image of the rhizome has been used in educational theory, but this use has not yet led to cartographic analysis. Because of their multiple connections, rhizomatic knowledge structures are difficult to represent in traditional, more linear text. Cartographically, however these multiple connections can both be represented and questioned. When one attempts to map 
rhizomatic processes or texts, one may discover other nodes and connections not previously realized, or one may question the position assigned to certain actors in the web. Patti Lather (1996) asks "what is the desire to be the subject of one's own knowledge in the face of the rhizomatic dispersion of knowledges across unequal cultural transfers?" (p. 364), and I wonder: How might one map this rhizomatic dispersion of knowledges? What difficulties might one run into in this mapping exercise? From whose perspective will the map be drawn, and where will be boundaries be? Inna Semetsky (2003) proposes a shift in thinking from the more static noun "knowledge" to the more dynamic verb "knowing." She connects Deleuze and Guattari's analysis of the rhizome with John Dewey's ideas about education as a growth process that should enable future growth. She proposes the development of a more fluid pedagogical space in which curriculum can emerge rhizomatically: "the multiple rhizomatic connections, produced within each 'here-and-now' (Deleuze, 1994, p. xx) of every single experiential situation, serve themselves as a precondition for the emergence of 'ever new, differently distributed 'heres' and 'nows"' (Deleuze, 1994, p. xxi)" (Semetsky, 2003, p. 27). And I wonder: What might such rhizomatic connections, and the offshoots to new 'heres' and 'nows' look like? How might they be visualized for students in education attempting to grasp this different way of thinking, especially if one does not want to freeze this process in a static image but seeks to capture the moving nature of the network? What new connections or dead ends will become visible in the mapping exercise?

\section{Reading and writing hypertext}

The third reason for exploring the possibilities of cartography in educational theory is the increased use of hyperlinked information in both educational theory and practice. When information is hyperlinked rather than organized in traditional, more linear, ways, both reading and writing practices change. Some celebrate the possibilities that information technology has opened up, liberating writers from linear narrative constraints and empowering readers to chart their own course through a text. Others lament these changes, arguing, for example, that common uses of computers, such as web navigation and the use of hypertext, "undermine people's ability to tell, enjoy listening to, view, and read good stories" (Gordon \& Alexander, 2005, p. 134). Whatever one's stance towards hypertext, it is unlikely that it will disappear any time soon, including from educational contexts. In order to explain, critique, and improve hypertextual reading and writing practices in education, cartographic representations are useful. Mapping the actual reading and writing patterns allows for a more concrete discussion of what is lost and gained. 
Figure 4. Wikipedia web browse (September $29,2005)$ starting with "John Dewey"

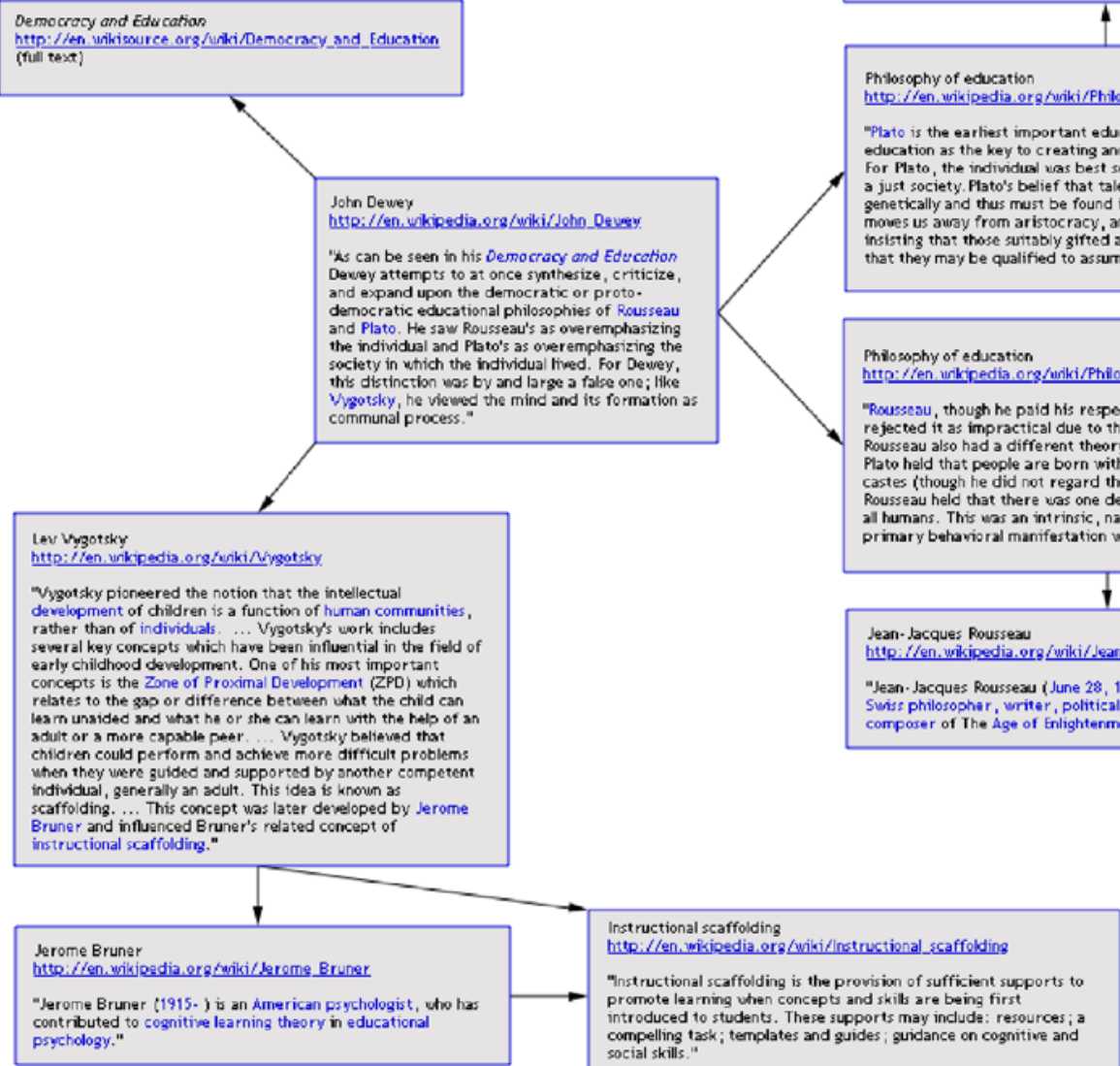

It is interesting, however, to consider one of Gordon and Alexander's claims in more detail. They argue, following theorists such as Charles Taylor and Alasdair MacIntyre, that narrative sensibility, the abovementioned "ability to tell, enjoy listening to, view, and read good stories," is a requirement for moral selfhood (p. 136). Human beings can only decide upon a course of action if they can place themselves in stories that give meaning to their lives. The inability to conceive of one's self as a story connected with the stories of other selves, they conclude, is a threat to moral selfhood and moral action. I wonder, however, whether the ability to connect one's own life and concerns to the lives and concerns of others is not more important than the narrative structuring of those lives and concerns. A good friend and colleague who has taught a course on multiculturalism and race relations in education for many years, commonly asks his students at the beginning of the course to respond to the question "Who are you? What is your identity?" 
Some students choose to respond narratively, but many create identity-maps that allow them to represent multiple belongings and allegiances, and the intersections or barriers between them. Are the moral selves of these thoughtful students in danger, or can a more serious consideration of cartographic discourse show us that these identity-maps, too, are a way of meaningfully and morally connecting ourselves with others?

\section{Mapping social positions: a spatial analysis of mechanisms of power}

The fourth reason for exploring the possibilities of cartography in educational theory is that education plays a central role in the social positioning of subjects. Michel Foucault (1975/1977) has analyzed the mechanisms deployed in social institutions such as industry, health care, education, and the penal system, especially in the discourses associated with those institutions, and in their buildings: the factory, the hospital, the school, and the prison.

Elementary and secondary schooling are concerned not only with students' minds, but also with the distribution and management of their bodies. Kelleen Toohey (2000) has analyzed the management of spatial relations in a grade 1 classroom. Toohey's analysis is based on many hours of classroom observation; in her book she provides a map of the seating arrangement she has observed to assist the reader in following her analysis and argument.

Figure 5. Toohey, 2000, p. 82

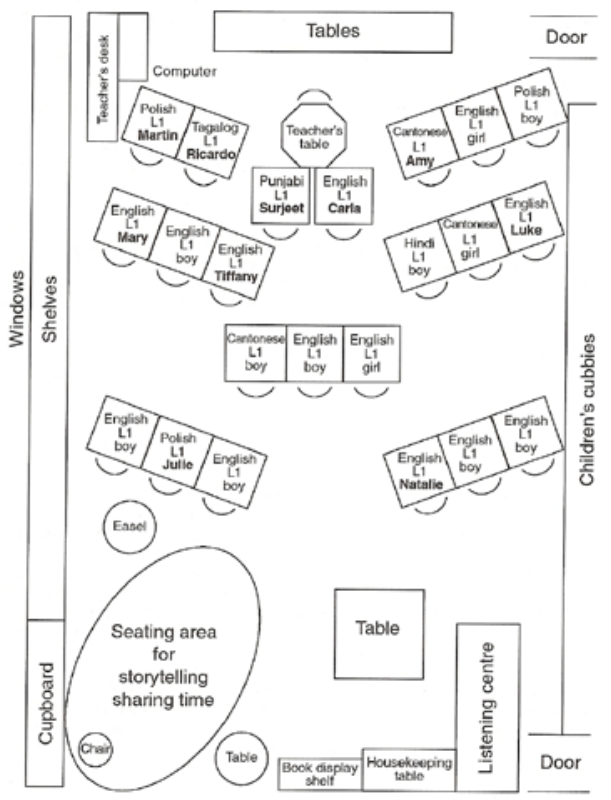


Requiring children to work at desks assigned by the teacher is a very common practice of primary classrooms. In this classroom, the practice obviously controlled which children were in proximity with one another, brought some children under close teacher surveillance, and disrupted verbal interactions for some-but not all-of the children. ... 'Marginalisation' is the customary, but in this case inept, metaphor. In truth, being on the margins, farther from teacher surveillance, in some ways put a child in a more powerful position; one had more autonomy in choosing one's own activities and verbal participation than when one was more centrally located with regard to the teacher. (pp. 89-91).

Both classrooms and the school buildings in which they are housed have commonly been designed according to panoptic principles (Foucault, 1975/1977). The privilege of invisibility, the possibility of escape from surveillance, is not a factor only within the classroom, but also within the school as a whole (and, increasingly, throughout urban public spaces).

Maps might also serve to highlight more covert ways in which mechanisms of power position students. Students are positioned not only physically but also socially by discursive classifications and hierarchies for which Foucault's analysis is equally powerful. Christine Sleeter's (1987) critical analysis of the emergence of the category of "learning disabilities" is a case in point. If one were to map the various discursive categories that precede and surround the category of "learning disability," such as "mentally retarded," "slow learner," "perceptually handicapped," and "socially maladjusted" how would they be positioned: in what proximity to one another, and with what categories at the center and the margins? How permeable would the boundaries be, and how would the categories overlap or intersect with other categories, such as race, class, and gender?

\section{Some limitations to cartography in educational theory}

Cartographic discourse is not a replacement for other discourse in educational theory and research texts. It is, as I have argued, a complementary or alternative discourse. Even as alternative or complementary discourse, however, its use runs into significant practical difficulties. Most people simply lack "carto-literacy" of any level comparable with their literacy in other discourses (Harley, 1988, p. 278). The current communicative potency of cartographic discourse is obviously hindered by the commonly limited ability to read and write maps. Some educational theorists and researchers, however, may be able to use maps in the analysis phase of research and writing, even if they do not, as yet, use them in the dissemination phase. Increasing acceptance and, indeed, promotion of interdisciplinary work opens up possibilities for collaboration between educational scholars, artists, and cartographers. 
A second, and related, practical problem is that most educational scholars, at this point, have limited access to and are unfamiliar with computer software that can aid in the construction of maps. Mapping and hypertext software is not yet a common part of educational scholarly repertoire. Furthermore, file size and compatibility problems may complicate the exchange of computer-generated maps, and if moving images are required to capture configurational shifts over time, these problems are exacerbated. However, both commercially developed software such as Inspiration, iGrafx FlowCharter, and Storyspace, and freely available software such as FreeMind, Issue Crawler, and the Scalable Vector Graphics (SVG) Viewer can assist educational scholars in mapping and hypertext exercises. I predict that these scholars will also find that some of their students are already quite adept at using this kind of software and incorporating cartographic ideas into their research and writing.

In spite of the current practical limitations, cartographic discourse is a valuable tool for educational theory and research. It can aid educational scholars in examining the spatial aspects of educational experience to which narrative discourse, so predominant in education, may not pay much attention. It can also visualize, hence make available for analysis and critique, spatial metaphors such as the web and network that are increasingly popular in educational discourse. Related to this is the ability of cartographic discourse to aid in the examination of the uses and effects of hypertextual reading and writing practices in education. Finally, cartographic discourse is a relevant analytic tool in the questioning of the physical and discursive mechanisms that are deployed in education and that play an important role in the social positioning of students.

Hic non sunt dracones.

\section{Acknowledgments}

An earlier version of this paper was presented at the 2006 annual meeting of the Canadian Philosophy of Education Society in Toronto, ON. I am grateful to the anonymous reviewers of Complicity for their helpful suggestions for improvement.

\section{References}

Austin, J. L. 1962. How to do things with words. Oxford: Oxford University Press. Braidotti, R. 2005. A critical cartography of feminist post-postmodernism. Australian Feminist Studies 20(47): 169-180.

Butler, J. 1993. Bodies that matter: On the discursive limits of "sex." New York: Routledge.

Capra, F. 1982. The turning point: Science, society, and the rising culture. New York: Bantam. 
Castells, M. 1996. The rise of the network society: The information age: Economy, society and culture, Volume I. Cambridge, MA: Blackwell Publishers.

Connelly, F. M. \& Clandinin, D. J. 1990. Stories of experience and narrative inquiry. Educational Researcher 19(5): 2-14.

Davis, B., Phelps, R., \& Wells., K. 2004. Complicity: An introduction and a welcome. Complicity: An International Journal of Complexity and Education 1(1), 1-7.

De Certeau, M. 1984. The practice of everyday life (S. Rendall, Trans.). Berkeley: University of California Press.

Deleuze, G. \& Guattari, F. 1987. A thousand plateaus: Capitalism and schizophrenia, trans. B. Massumi. Minneapolis: University of Minnesota Press.

D'Ignazio, Catherine (kanarinka). 2005, January 1. Re: Questioning the Frame. Retrieved on September 23, 2005 from HYPERLINK, http: / / permalink.gmane. org / gmane.culture.internet.nettime/ 280

Fischman, G. E. 2001. Reflections about images, visual culture, and educational research. Educational Researcher 30(8), 28-33.

Foucault, M. 1977. Discipline and punish: The birth of the prison, trans. A. Sheridan. New York: Vintage Books.

Gordon, D. \& Alexander, G. 2005. The education of story lovers: Do computers undermine narrative sensibility? Curriculum Inquiry 35(2): 133-159.

Harley, J. B. 1988. Maps, knowledge, and power. In The iconography of landscape: Essays on the symbolic representation, design and use of past environments, edited by D. Cosgrove \& S. Daniels, 277-312. Cambridge, UK: Cambridge University Press.

Harley, J. B. 2001. Deconstructing the map. In The new nature of maps: essays in the history of cartography, edited by J. B. Harley \& P. Laxton, 150-168. Baltimore, MD: The Johns Hopkins University Press.

Lather, P. 1996. Postcolonial feminism in an international frame: From mapping the researched to interrogating mapping. In Social cartography: Mapping ways of seeing social and educational change, edited by R. G. Paulston, 357-373. New York: Garland.

Lather, P. 1996. Troubling clarity: The politics of accessible language. Harvard Educational Review 66(3): 525-545.

Lather, P. \& Smithies, C. 1997. Troubling the angels: Women living with HIV/AIDS. Boulder, CO: Westview Press.

Liebman, M. 1996. Envisioning spatial metaphors from wherever we stand. In Social cartography: Mapping ways of seeing social and educational change, edited by R. G. Paulston, 191-215. New York: Garland.

Martusewicz, R. A. 2001. Seeking passage: Post-structuralism, pedagogy, ethics. New York: Teachers College Press.

Metcalfe, A. 2006. The corporate partners of higher education associations: A social network analysis. Industry and Innovation 13(4): 459-479.

On, J. 2004. They rule 2004. Retrieved on February 24, 2006 from http:/ /www. theyrule.net.

Ormell, C. 1996. Eight metaphors of education. Educational Research 38(1): 67-75.

Paulston, R. G. 1996. Preface: Four principles for a non-innocent social cartography. In Social cartography: Mapping ways of seeing social and educational change, edited by R. G. Paulston, pp. xv-xxiv. New York: Garland. 
Paulston, R. G. 1999. Mapping comparative education after postmodernity. Comparative Education Review 43(4): 438-463.

Paulston, R. G. \& Liebman, M. 1994. An invitation to postmodern social cartography. Comparative Education Review 38(2): 215-232.

Ricoeur, P. 1984. Time and narrative, Vol. 1, trans. K. McLaughlin and D. Pellauer. Chicago: Chicago University Press.

Sarup, M. 1998. An introductory guide to post-structuralism and postmodernism (2nd ed.). Toronto, ON: Harvester Wheatsheaf.

Scott, J. 1997. Deconstructing equality-versus-difference: Or, the uses of poststructuralist theory for feminism. In Feminist social thought: A reader, edited by D. Tietjens Meyers, 758-770. New York: Routledge.

Semetsky, I. 2003. Deleuze's new image of thought, or Dewey revisited. Educational Philosophy and Theory 35(1): 17-29.

Seppi, J. R. 1996. Spatial analysis in social cartography: Metaphors for process and form in comparative educational studies. In Social cartography: Mapping ways of seeing social and educational change, edited by R. G. Paulston, 121-139. New York: Garland.

Sleeter, C. E. 1987. Why is there learning disabilities? A critical analysis of the birth of the field in its social context. In The formation of school subjects: The struggle for creating an American institution, edited by T. S. Popkewitz, 210-237. New York: The Falmer Press.

Stein, J. G. 2001. The cult of efficiency. Toronto, ON: House of Anansi Press.

Toohey, K. 2000. Learning English at school: Identity, social relations and classroom practice. North York, ON: Multilingual Matters.

Usher, R. 2002. Putting space back on the map: Globalisation, place and identity. Educational Philosophy and Theory 34(1): 41-55.

\section{About the author}

Claudia W. Ruitenberg is assistant professor in the Department of Educational Studies at the University of British Columbia. Her primary areas of interest are poststructuralist philosophy and speech act theory, identity and identity politics in education, gender issues and queer theory, aesthetic education, and intersections of education and cultural studies. Email: claudia.ruitenberg@ubc.ca URL: http: / / edst. educ.ubc.ca/faculty/ ruitenberg.htm

(C) Copyright 2007. The author, CLAUDIA W. RUITENBERG, assigns to the University of Alberta and other educational and non-profit institutions a non-exclusive license to use this document for personal use and in courses of instruction provided that the article is used in full and this copyright statement is reproduced. The authors also grant a nonexclusive license to the University of Alberta to publish this document in full on the World Wide Web, and for the document to be published on mirrors on the World Wide Web. Any other usage is prohibited without the express permission of the author. 